\title{
Caspase-dependent and -independent suppression of apoptosis by monoHER in Doxorubicin treated cells
}

\author{
AME Bruynzeel',', MA Abou El Hassan ${ }^{1,2}$, E Torun', A Bast ${ }^{3}$, WJF van der Vijgh ${ }^{1,3}$ and FAE Kruyt ${ }^{1}$ \\ 'Department of Medical Oncology, VU University Medical Center, 1081 HV, Amsterdam, The Netherlands; ${ }^{2}$ Cancer Biology Department, National \\ Cancer Institute, Cairo University, Cairo, Egypt; ${ }^{3}$ Department of Pharmacology and Toxicology, Faculty of Medicine, University of Maastricht, 6200 MD, \\ Maastricht, The Netherlands
}

\begin{abstract}
Doxorubicin (DOX) is an antitumour agent for different types of cancer, but the dose-related cardiotoxicity limits its clinical use. To prevent this side effect we have developed the flavonoid monohydroxyethylrutoside (monoHER), a promising protective agent, which did not interfere with the antitumour activity of DOX. To obtain more insight in the mechanism underlying the selective protective effects of monoHER, we investigated whether monoHER (I mM) affects DOX-induced apoptosis in neonatal rat cardiac myocytes (NeRCaMs), human endothelial cells (HUVECs) and the ovarian cancer cell lines A2780 and OVCAR-3. DOX-induced cell death was effectively reduced by monoHER in heart, endothelial and A2780 cells. OVCAR-3 cells were highly resistant to DOXinduced apoptosis. Experiments with the caspase-inhibitor zVAD-fmk showed that DOX-induced apoptosis was caspase-dependent in HUVECs and A2780 cells, whereas caspase-independent mechanisms seem to be important in NeRCaMs. MonoHER suppressed DOX-dependent activation of the mitochondrial apoptotic pathway in normal and A2780 cells as illustrated by p53 accumulation and activation of caspase- 9 and -3 cleavage. Thus, monoHER acts by suppressing the activation of molecular mechanisms that mediate either caspase-dependent or -independent cell death. In light of the current work and our previous studies, the use of clinically achievable concentrations of monoHER has no influence on the antitumour activity of DOX whereas higher concentrations as used in the present study could influence the antitumour activity of DOX.

British Journal of Cancer (2007) 96, 450 -456. doi:I0.I038/sj.bjc.6603598 www.bjcancer.com
\end{abstract}

(C) 2007 Cancer Research UK

Keywords: monoHER; doxorubicin; apoptosis; caspases; (non) tumour cells

Doxorubicin (DOX) is highly effective against various types of cancers, including leukaemias, breast and ovarian cancer. Doxorubicin (DOX) induces pleiotropic cytotoxic effects of which DNA intercalation and topoisomerase II inhibition have been proposed to play an important role in its mechanism of action, causing growth arrest and the subsequent activation of apoptosis (Capranico et al, 1990; Gewirtz, 1991; Binaschi et al, 1997). The contribution of DOX-induced reactive oxygen species (ROS) to its antitumour activity is still a matter of debate (Keizer et al, 1991; Shacter et al, 2000; Gouaze et al, 2001; Suresh et al, 2003).

A major limitation of the use of DOX in the clinic is its cumulative dose-related cardiotoxicity, which ultimately can lead to severe and irreversible forms of cardiomyopathy (Lefrak et al, 1973; Singal and Iliskovic, 1998; Hrdina et al, 2000). Doxorubicin (DOX)-induced ROS have been shown as the primary cause of the heart damaging effect of the drug (Horenstein et al, 2000; Xu et al, 2001). In addition, several studies suggested that DOX-induced apoptosis in endothelial cells and cardiomyocytes contributes to the development of DOX-related cardiotoxicity (Childs et al, 2002;

*Correspondence: Dr AME Bruynzeel, 2 PK BR 0 I0, VU Medical Center, De Boelelaan I1 17, 1081 HV Amsterdam, The Netherlands;

E-mail: ame.bruynzeel@vumc.nl

Revised I4 December 2006; accepted 19 December 2006
Wu et al, 2002; Kluza et al, 2004; Spallarossa et al, 2004). Various strategies have been developed to protect against DOX-induced cardiotoxic effects. The majority of these studies concern either metal ion chelators or antioxidants that yielded moderate protective effects (Swain et al, 1997; Kotamraju et al, 2000; Liu et al, 2002; Yamanaka et al, 2003; Oliveira et al, 2004).

MonoHER - a semisynthetic flavonoid that was developed in our laboratory (Willems et al, 2006) and presently in a phase II clinical trial is both a radical scavenging and a metal ion chelating agent (Haenen et al, 1993; van Acker et al, 1993). In our studies the scavenging activity of monoHER was measured by determining the inhibition of ferricytochrome $c$ reduction and the inhibition of oxygen consumption, showing an inhibition of 91 and $70 \%$, respectively (van Acker et al, 1993). Because of these favourable properties, monoHER was tested as a protectant against DOX-induced cardiac damage in in vivo models and appeared a potent protector against DOX-induced cardiotoxicity without influencing its antitumour effects (van Acker et al, 1997, 2000).

The present study was initiated to determine possible differences in the effects of monoHER against DOX-induced apoptosis in cardiac myocytes and vascular endothelial cells in comparison to ovarian cancer cell lines. The protective effects of monoHER on cell cycle progression and molecular determinants of mitochondrial-dependent apoptosis were also studied. The clinical relevance of our results regarding the use of protectors such as monoHER in combination with chemotherapy is discussed. 


\section{MATERIALS AND METHODS}

\section{Chemicals}

7-Monohydroxyethylrutoside (monoHER) was kindly provided by Novartis Consumer Health (Nyon, Switzerland). Doxorubicin $\mathrm{HCl}$ was purchased from Pharmacia Upjohn BV (Woerden, the Netherlands). The following reagents were used in this study: bovine serum albumin, trypsin, 3-(4,5-dimethylthiazol-2-yl)-2,5diphenyltetrazolium bromide (MTT) and sodium vanadate $\left(\mathrm{NaVO}_{3}\right)$ (all from Sigma-Aldrich Chemie (Zwijndrecht, the Netherlands)); human serum (Central Laboratory for Blood Transfusion, Amsterdam, the Netherlands); M199 medium and Hanks Balanced salt solution (without calcium) (Invitrogen, Breda, the Netherlands); Dulbecco's modified Eagle's medium (DMEM) and HEPES (Cambrex Bio Science, New Jersey, USA); fetal calf serum (FCS) (Greiner Bio-One B.V., Alphen a/d Rijn, the Netherlands); Na-penicillin-G (Yamanouchi Pharma B.V., the Netherlands); streptomycin (Fisiopharma, Milano, Italy); L-glutamine (ICN Biochemicals, Cleveland, Ohio, USA); horse serum (Life Technologies NV, Merelbeke, Belgium); glycerol (J.T. Baker, Europe, Deventer, the Netherlands); protease inhibitor tablets (Roche Diagnostics Netherland BV, Almere, the Netherlands); Benzyloxycarbonyl-Val-Ala-Asp-fluoromethyl keton (z-VAD) (Enzyme Systems, Livermore, CA, USA); Endothelial cell growth factor (ECGF) was extracted from bovine hypothalamus as described previously (Maciag et al, 1979).

\section{Cell culture}

All cells were maintained at $37^{\circ} \mathrm{C}$ in humidified air containing $5 \%$ $\mathrm{CO}_{2}$. A2780 and OVCAR-3 cells were grown in DMEM with $10 \%$ FCS and $20 \mathrm{~mm}$ HEPES. Human endothelial cells (HUVECs) were prepared as described previously by Verheul et al (2000). In brief, the endothelial cells were cultured in gelatin-coated (1\%) tissue culture plates with culture medium consisting of M199 supplemented with $10 \%$ human serum, $10 \% \mathrm{FCS}, 5 \mathrm{U} \mathrm{ml}^{-1}$ heparin, $200 \mathrm{IE} \mathrm{ml}^{-1}$ penicillin and $200 \mu \mathrm{g} \mathrm{ml}^{-1}$ streptomycin, $0.29 \mathrm{mg} \mathrm{ml}^{-1} \mathrm{~L}$-glutamine and $50 \mu \mathrm{g} \mathrm{ml}^{-1}$ ECGF. Cells were grown to confluence at $37^{\circ} \mathrm{C}$ in $5 \% \mathrm{CO}_{2}$. Endothelial cells after three passages (P3) were used during the whole study. Neonatal rat cardiac myocytes (NeRCaMs) were isolated as described previously by (Abou El Hassan et al, 2003a). The cardiac cells were divided over tissue culture plates with a cell density of $75 \times 10^{3}$ cells cm$^{-2}$. After plating, the cells were incubated with medium consisting of equal portions of DMEM and Ham's F-10 supplemented with $100 \mathrm{U} \mathrm{ml}^{-1}$ penicillin, $100 \mu \mathrm{g} \mathrm{ml}^{-1}$ streptomycin and $5 \%$ horse serum. The cultures contained at least $90 \%$ of synchronously beating NeRCaMs. After $24 \mathrm{~h}$ the medium was refreshed and $48 \mathrm{~h}$ later the NeRCaM cultures were ready for use in the experiments.

\section{Flow cytometric analysis of PI-stained cells}

Cardiac myocytes, endothelial, A2780 and OVCAR-3 cells were treated with different concentrations of DOX $(0.1-10 \mu \mathrm{M})$ alone or in the presence of $1 \mathrm{~mm}$ monoHER for $48 \mathrm{~h}$, respectively. Apoptotic cell fraction (sub-G1) in PI-stained cells was measured by flow cytometry as described previously (Swain et al, 1997; Suresh et al, 2003). In brief, after trypsinisation the cells were resuspended in PI staining solution $\left(50 \mu \mathrm{M} \mathrm{ml}^{-1} \mathrm{PI}, 0.1 \%\right.$ sodium citrate, $0.1 \%$ TritonX-100, $0.1 \mathrm{mg} \mathrm{ml}^{-1}$ Rnase in PBS). The cells were incubated for at least $30 \mathrm{~min}$ at $4^{\circ} \mathrm{C}$ in the dark before analysis by flow cytometry using a FACScan (Becton, Dickinson and Company, NJ, USA). When indicated cells were pretreated for $1 \mathrm{~h}$ with $50 \mu \mathrm{m}$ of the broad caspase inhibitor $\mathrm{z}$-VAD-fmk before DOX exposure or co-treated with monoHER (1 mM).

\section{Western blot analysis}

Cells were treated with DOX with or without $1 \mathrm{~mm}$ MonoHER for 24 and $48 \mathrm{~h}$ at $37^{\circ} \mathrm{C}$. The cells were trypsinised and lysed for $20 \mathrm{~min}$ on ice in lysis buffer consisting of $20 \mathrm{~mm} \mathrm{HEPES} / \mathrm{KOH}(\mathrm{pH} 7.4$ ), $50 \mathrm{~mm} \beta$-glycerophosphate, $50 \mathrm{~mm} \mathrm{KCl}, 0.2 \mathrm{~mm}$ EDTA, $1 \%(\mathrm{w} / \mathrm{v})$ Triton $\mathrm{X}-100$, and $10 \%(\mathrm{w} / \mathrm{v})$ glycerol, supplemented with protease inhibitors and $1 \mathrm{~mm} \mathrm{NaVO}_{3}$. Protein concentrations were determined using the Bio-Rad assay (Bio-Rad Laboratories, Richmond, CA, USA) with BSA as a standard using a spectrophotometer. Equal amounts of protein $(15 \mu \mathrm{g})$ were loaded and electrophoresed on 7-12\% SDS-polyacrylamide gels and transferred into polyvinylidene difluoride membranes (Amersham, Braunschweig, Germany). Subsequently, membranes were blocked with $5 \%$ nonfat dry milk for $1 \mathrm{~h}$ at room temperature and incubated at $4{ }^{\circ} \mathrm{C}$ overnight with the indicated primary antibodies followed by a $1 \mathrm{~h}$ incubation at room temperature with a secondary antibody, either horseradish peroxidase-conjugated goat anti-mouse or goat antirabbit antibodies $(1: 2000)$. Protein loading equivalence was assessed by the expression of $\beta$-actin $(1: 10000)$. Proteins were visualised by enhanced chemiluminescence (ECL kit, Amersham, Braunschweig, Germany). Primary antibodies used were against p53 (human specific, DAKO, Glostrup, Denmark), poly(ADPribose) polymerase (PARP) (Roche Diagnostics Netherland BV, Almere, the Netherlands), caspase- 9 (human specific or mouse $\mathrm{mAb}$ ), p53 and PARP (rat specific, all from Cell Signaling Technology Inc., Beverly, MA, USA), Bax and caspase-3 (BD Transduction Laboratories NJ, USA) and $\beta$-actin (Sigma-Aldrich Chemie, Zwijndrecht, the Netherlands).

\section{RESULTS}

\section{Effect of monoHER on DOX-induced apoptosis}

Normal cells were more sensitive to DOX-induced apoptosis than the selected tumour cell lines. The $\mathrm{IC}_{50}$ values were $0.75,0.5$ and $1.5 \mu \mathrm{M}$ for HUVECS, NeRCaMs and A2780 cells, respectively. However, OVCAR-3 was highly resistant with a maximum of only $10-12 \%$ cells in sub-G1 phase at $10 \mu \mathrm{M}$ (Figure 1 and Table 1 ). HUVECs were relatively resistant to low concentrations of DOX and reached a plateau of apoptotic cell fraction at a concentration of $1 \mu \mathrm{M}$. NeRCaMs displayed a gradual dose-dependent increase of apoptotic cells at low DOX concentrations reaching a plateau of $60 \%$ killing at $1 \mu \mathrm{M}$ DOX. A2780 cells also showed a dosedependent increase in apoptotic cells, reaching a plateau of about $50 \%$ at DOX concentrations $\geqslant 1 \mu \mathrm{M}$. The ratios of the $\mathrm{IC}_{50}$ values shown in Table 1 indicate that $1 \mathrm{~mm}$ MonoHER protected 13- and 15-fold against DOX-induced apoptosis in HUVECs and NeRCaMs, respectively. A2780 cells were only protected with a factor 5.3, whereas OVCAR-3 did not show any protection by monoHER.

\section{Doxorubicin-induced caspase activation}

The differences found in sensitivity to the apoptotic effects of DOX in the examined cell panel prompted us to investigate the role of caspases in mediating cell death. To that purpose, HUVECs, NeRCaMs, A2780 and OVCAR-3 cells were treated with $1 \mu \mathrm{M}$ DOX with or without the addition of the broad-spectrum caspase inhibitor z-VAD-fmk (Figure 1C). A strong suppression (leaving only $15 \%$ apoptotic cells) was observed in HUVECs whereas no significant protection was observed in NeRCaMs. In tumour cells, $\mathrm{z}$-VAD-fmk almost completely protected against the moderate apoptotic effects of DOX in A2780 cells (only 10\% apoptotic cells left). Z-VAD-fmk exhibited no significant protection against DOXinduced apoptotic effects in OVCAR-3; however the interpretation of this finding is difficult in light of the strong apoptosis resistance found in these cells. Taken together, these results indicate that DOX-induced apoptosis in HUVECs and A2780 cells was 

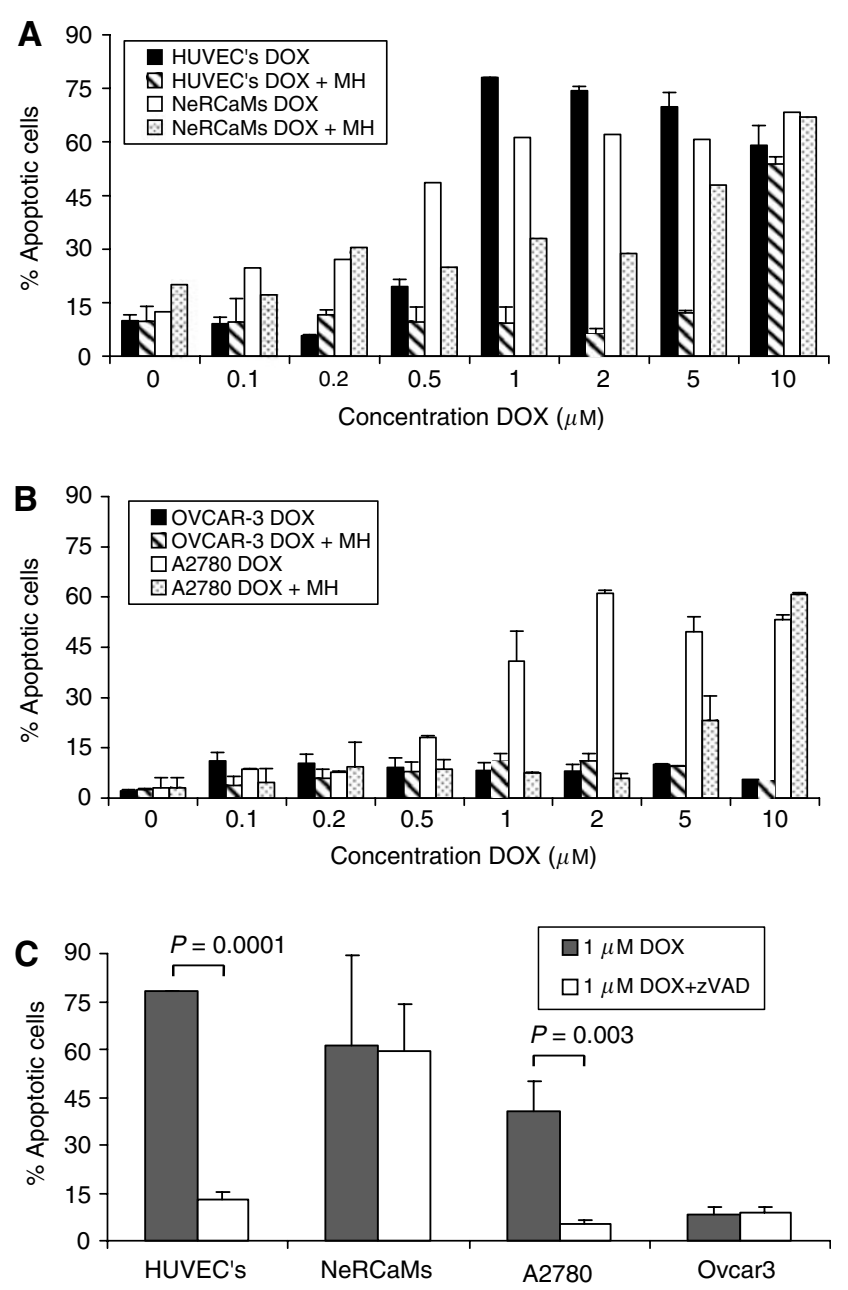

Figure I The effect of monoHER (I mM) on DOX-induced apoptosis in cardiomyocytes (NeRCaMs), endothelial cells (HUVECs) (A) and ovarian tumour cells A2780 and OVCAR-3 (B) after $48 \mathrm{~h}$ of incubation. The bars indicate the levels of the sub-GI cell fractions of apoptotic cells after Pl staining. The effect of $50 \mu \mathrm{M}$ zVAD-fmk (a broad-spectrum caspase inhibitor) on DOX (I $\mu \mathrm{M}, 48 \mathrm{~h}$ )-induced cell death was also investigated (C). Results are presented as the mean $( \pm s$.d.) of three independent experiments except for the NeRCaMs in Figure IA, where results of two experiments are shown.

Table I IC 50 values $(\mu \mathrm{M})$ for endothelial (HUVECs), cardiac cells (NeRCaMs), OVCAR-3 and A2780 cells

\begin{tabular}{lccc}
\hline Cell type & DoX & DoX+MH & Fold protection \\
\hline HUVECs & 0.75 & 10 & 13 \\
NeRCaMs & 0.5 & 7.5 & 15 \\
A2780 & 1.5 & 8 & 5.3 \\
OVCAR-3 & $>10$ & $>10$ & - \\
\hline
\end{tabular}

principally mediated by caspases, whereas NeRCaMs and OVCAR3 cells displayed less or hardly any contribution of caspases to DOX toxicity. In addition, the effect of a higher dose of DOX $(10 \mu \mathrm{M})$ with or without the addition of $\mathrm{z}-\mathrm{VAD}$-fmk was examined inducing a more robust cell death than $1 \mu \mathrm{M}$ DOX. Under these conditions, z-VAD-fmk showed comparable results as obtained at $1 \mu \mathrm{M}$ DOX (results not shown).

\section{Cell cycle effects of DOX treatment}

The effect of the combined treatment of DOX $(1 \mu \mathrm{M}, 48 \mathrm{~h})$ with monoHER or $\mathrm{z}$-VAD-fmk on cell cycle progression in the panel of non-tumour and tumour cells was determined by FACS analysis of PI-stained cells (Figure 2). Doxorubicin (DOX) alone induced apoptosis as illustrated by the accumulation of cells in sub-G1. HUVECs were most sensitive to DOX and monoHER-dependent suppression of DOX-induced sub-G1 accumulation was clearly accompanied by G2/M arrest. The cell cycle profile obtained after caspase inhibition displayed accumulation of HUVECs in all cell cycle phases with a distribution resembling that of untreated control cells. In NeRCaMs co-exposure with monoHER protected against apoptosis, and a small increase in $G 2 / \mathrm{M}$ accumulation was observed. A2780 tumour cells showed strong accumulation in G2/M upon apoptosis suppression by cotreatment with monoHER; $\mathrm{z}-\mathrm{VAD}$-fmk also led to G2/M accumulation and strong S-phase arrest. In apoptosis-resistant OVCAR-3 cells DOX mediated an S-phase arrest that was strongly prevented by monoHER, leading to a large accumulation in G2/M. Cotreatment with $\mathrm{z}-\mathrm{VAD}$-fmk resulted in accumulation of cells in the $\mathrm{G} 2 / \mathrm{M}$ phase.

Taken together, it appears that monoHER delays DOX-treated cells in the G2/M phase, particularly in the examined tumour cells. Caspase inhibition by $\mathrm{z}$-VAD-fmk was most notable in HUVECs where DOX apoptotic effects seem to be merely caspasedependent, whereas other cell types showed partial inhibition or in case of OVCAR-3 almost no effect at all. Although both monoHER and z-VAD-fmk had overlapping effects on the cell cycle distribution of DOX-treated cells, mainly G2/M accumulation, z-VAD-fmk resulted also in the delay of the tumour cells in the $S$ phase, and in the G1 phase in case of HUVECs or NeRCaMs. Because monoHER can suppress DOX cytotoxicity in all these cells it apparently suppresses both caspase-dependent and -independent forms of cell death.

\section{Effect of monoHER on DOX-dependent activation of p53, Bax and caspases}

To obtain more insight into the molecular mechanism underlying the apoptosis-inducing effect of DOX and the apoptosis suppressing effects of monoHER, the expression of several regulators and executors of apoptosis was studied in the panel of cells by Western blotting. To that purpose, cells were exposed to the corresponding $\mathrm{IC}_{50}$ concentrations of $\mathrm{DOX}$ in the presence or absence of monoHER for 24 and $48 \mathrm{~h}$.

In HUVECs (Figure 3A), DOX treatment resulted in an accumulation of $\mathrm{p} 53$ at $24 \mathrm{~h}$ exposure which decreased at 48 post-treatment, most probably caused by the strong activation of apoptosis resulting in the degradation of cellular proteins. This finding was supported by a decrease in $\beta$-actin levels. Interestingly, co-exposure with monoHER suppressed p53 accumulation. A small increase in p53 levels may be observed after $24 \mathrm{~h}$ treatment with monoHER alone, which was not detected after $48 \mathrm{~h}$. This increase was not seen in the other cells tested (see below). Although we have no clear explanation for this small increase it may reflect a more ROS-sensitive regulation of p53 in untreated HUVECs than in the other cells.

The pro-apoptotic Bcl2 family member Bax was constitutively expressed in untreated HUVECs and a shorter form of Bax of approximately $18 \mathrm{kDa}$ appeared after treatment with DOX probably representing a cleaved or truncated form. The occurrence of this shorter variant was, however, prevented by monoHER. As predicted by the $\mathrm{z}$-VAD-fmk sensitivity of DOX-induced apoptosis in these cells, robust caspase-9 and -3 cleavage was seen accompanied by processing of the caspase substrate PARP. MonoHER suppresses caspase activation. As controls, DMSO and monoHER alone did not trigger caspase activation. 
HUVECs
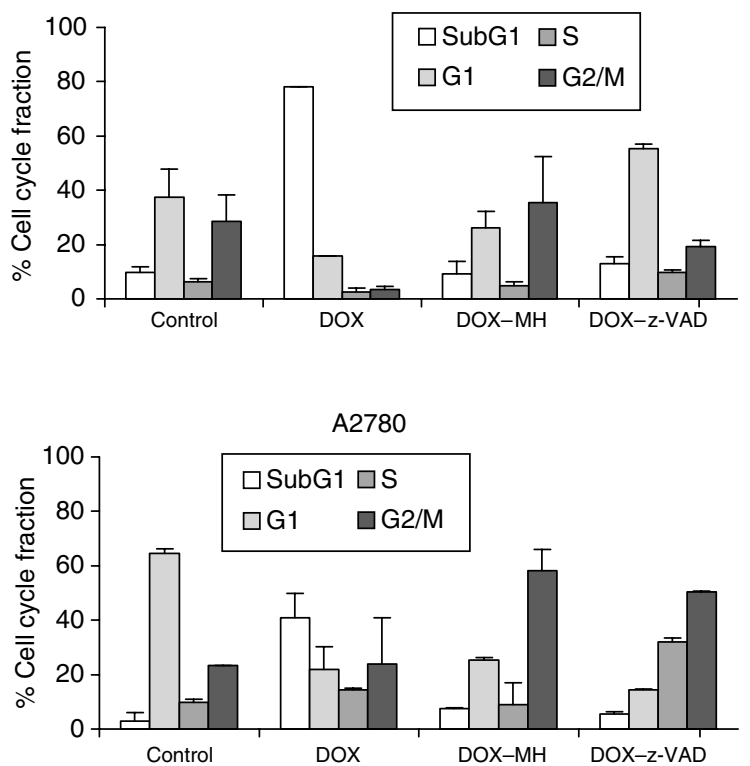

NeRCaMs

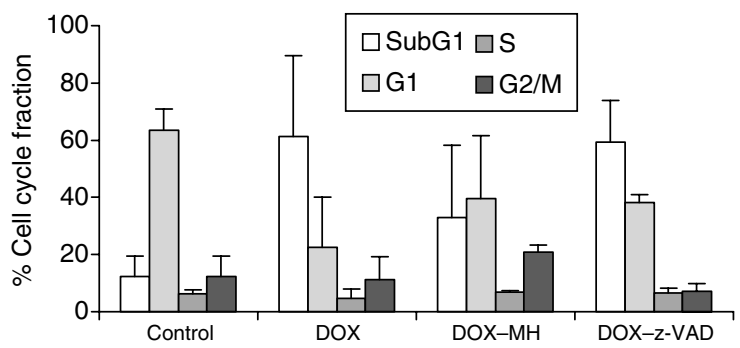

OVCAR-3

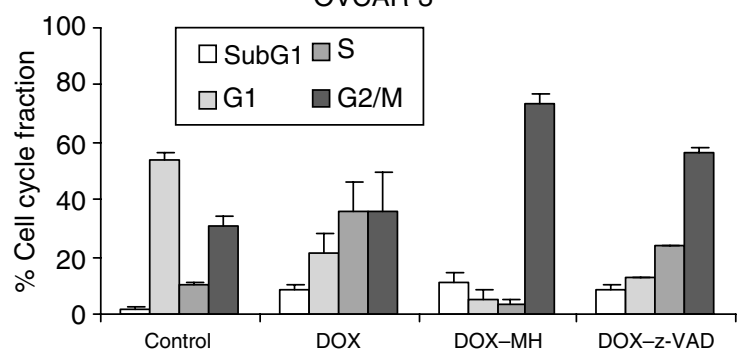

Figure 2 Effect of I mM monoHER and $50 \mu \mathrm{M}$ zVAD-fmk on cell cycle progression in cardiomyocytes, endothelial cells and ovarian cancer cells treated with I $\mu \mathrm{M}$ DOX for $48 \mathrm{~h}$. The percentage of cells in the different cell cycle fractions was determined by flow cytometry.

A

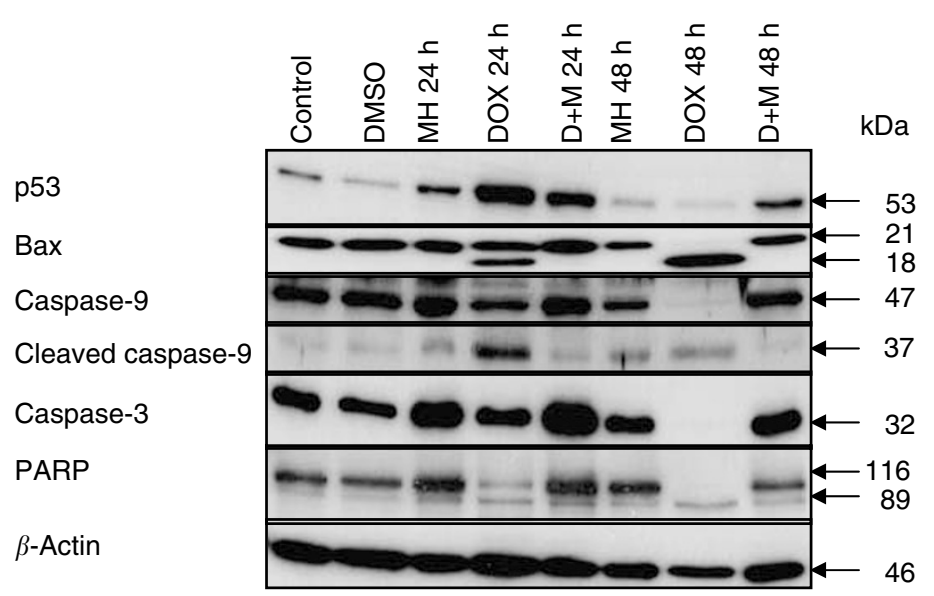

B

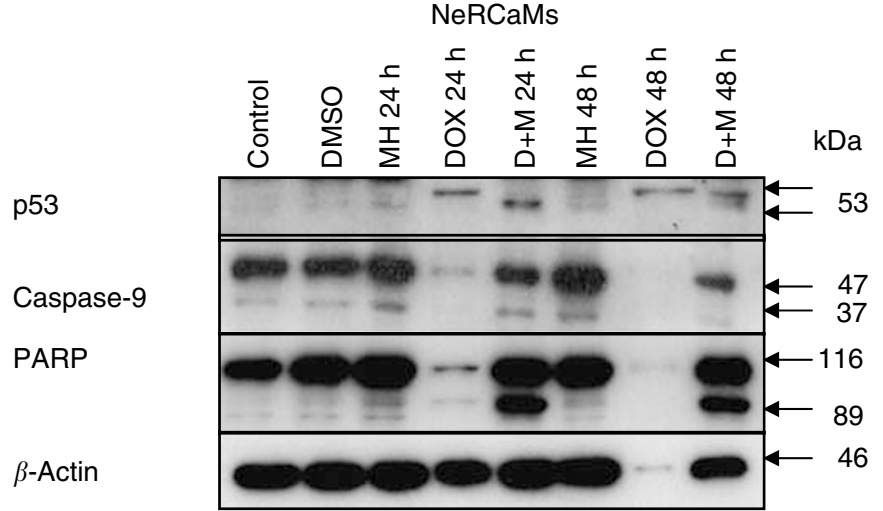

C

p53

Bax

Caspase-9

Caspase-3

PARP

$\beta$-Actin

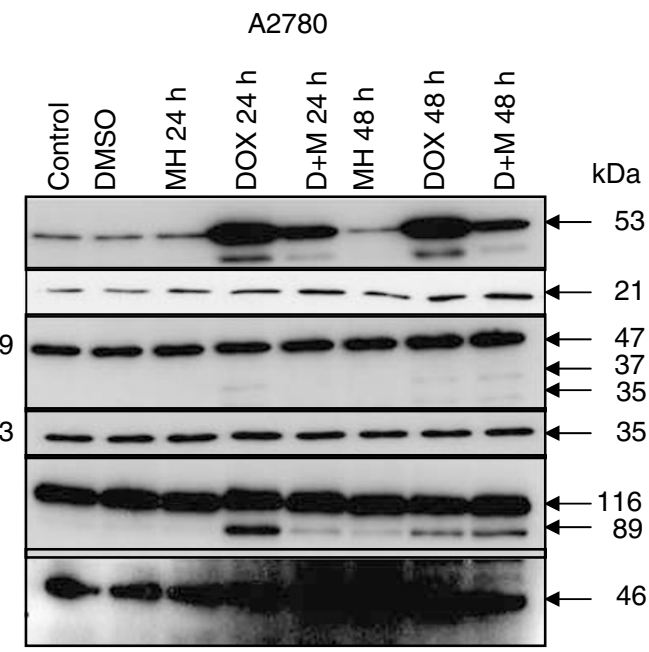

OVCAR-3

D p53 Bax

Caspase-9 Caspase-3 PARP $\beta$-Actin

Figure 3 Effect of monoHER on DOX-induced p53, Bax and caspase activation. The expression of the indicated proteins was examined by Western blotting in HUVECs $(\mathbf{A})$, NeRCaMs $(\mathbf{B})$, and in A2780 $(\mathbf{C})$ and OVCAR-3 tumour cells $(\mathbf{D})$ after 24 and $48 \mathrm{~h}$ of DOX exposure at their IC 50 . The molecular weight of the bands is indicated and $\beta$-actin was included as a control for protein loading. 
In NeRCaMs, p53 expression was only detectable after DOX treatment and monoHER appeared to influence the post-translational modification of p53 as indicated by changes in the mobility of the p53 specific bands (Figure 3B). Doxorubicin (DOX) potently triggered caspase- 9 activation as indicated by the strong decrease or even absence of the pro-form band at 24 and $48 \mathrm{~h}$ after treatment. Also strong PARP cleavage was observed. In light of the observed lack of effect of $\mathrm{z}$-VAD-fmk treatment on DOX-induced cell death this may suggest that a caspase-independent form of cell death can be activated in parallel in these cells. Regardless of this, monoHER very effectively suppressed caspase- 9 activation and PARP cleavage. We were not able to detect Bax or caspase-3 expression in NeRCaMs as the available antibodies did not crossreact with the rat counterparts.

Next, the ovarian cancer cell lines were investigated. A2780 cells (wild-type p53) showed clear DOX-induced p53 accumulation and PARP cleavage that could be suppressed by monoHER (Figure $3 \mathrm{C}$ ). However, the mechanism of DOX-induced caspase activation in A2780 cells was different from that in HUVECs, with no or hardly any Bax, caspase- 9 and -3 cleavage/activation, suggesting no primary role for the mitochondrial pathway in mediating DOXdependent apoptosis in these cells. Nonetheless, A2780 cells displayed clear PARP cleavage after DOX exposure. In contrast, OVCAR-3 cells showed little or no evidence for DOX-induced p53, Bax or caspase activation or PARP cleavage (Figure 3D). This was not unexpected because these cells contain mutant p53 and show resistance against apoptosis.

\section{DISCUSSION}

The antitumour effects of DOX results from preventing DNA replication and repair leading to cell cycle arrest and apoptosis (Capranico et al, 1990; Gewirtz, 1991; Binaschi et al, 1997). Doxorubicin (DOX)-induced cardiotoxicity was related to the activation of apoptosis in cardiomyocytes and endothelial cells (Wu et al, 2002; Yamanaka et al, 2003; Spallarossa et al, 2004). In these cells the main effects of DOX were mediated via the production of ROS, known for its potent cell damaging effects. Thus DOX-induced apoptosis, although via different routes, is a common mechanism in normal and cancer cells.

Interestingly, the potent ROS scavenger monoHER, which is presently in a clinical phase II study, showed a strong protection against the cardiotoxic effects of DOX without modulating its antitumour effects both in vivo and in vitro (van Acker et al, 1997; van Acker et al, 2000; Abou El Hassan et al, 2003a, d). The antiapoptotic role played by monoHER and the contribution to its selective protection is not studied yet. The present study was therefore aimed to compare the protective effects of monoHER against DOX-induced apoptosis in normal and cancer cells to unravel the mechanism of its selective protection.

Doxorubicin (DOX) induced concentration-dependent apoptosis both in HUVECs and NeRCaMs, which is in line with an earlier study (Wu et al, 2002). A2780 cells were also sensitive to induction of apoptosis by DOX, whereas OVCAR-3 cells were highly resistant. This resistance could be attributed to the presence of mutant p53, but may also be caused by other yet unknown apoptotic blockades. Employing the broad caspase inhibitor z-VAD-fmk revealed that DOX triggered caspase-dependent apoptosis in HUVECs and A2780 cells, and caspase-independent cell death in NeRCaMs. Combination treatment with monoHER was effective in suppressing both caspase-dependent (HUVECs and A2780) and -independent apoptosis (NeRCaMs). Assessment of the fold anti-apoptotic protection achieved showed that HUVECs and NeRCaMs were stronger protected by monoHER than A2780 cells. Examination of the molecular mechanisms that underlie the protective effects of monoHER indicated that it can strongly reduce the activation of DOX-induced p53 accumulation in cardiomyocytes, endothelial cells and A2780 cells, which contain wild-type p53 (Camarda et al, 2002), whereas as expected, no p53 response was detected in OVCAR-3 cells that express mutant p53. It is conceivable that the radical scavenging properties of monoHER cause the reduction of p53 accumulation, which is a known sensor of ROS-dependent toxicity (Uberti et al, 1999), leaving only topoisomerase 2-DNA damage as a trigger for p53 activation.

The suppressive effect of monoHER on the activation of caspase- 9 and -3 and the substrate PARP can also be explained by the neutralisation of ROS-dependent triggers of caspase activation. Evidence for mitochondria-dependent activation of caspases was only obtained in HUVECs, in which DOX exposure resulted in the occurrence of a shorter form of BAX, which was suppressed by monoHER. This shorter form may be produced by cleavage of full-length Bax or may represent an alternatively spliced variant with mitochondria destabilising activity leading to the apoptosome-dependent activation of caspase-9 and the subsequent activation of apoptotic cell death (Youn et al, 2005). In A2780 cells the mitochondrial pathway seemed to be less involved in DOX-induced apoptosis because DOX did not show clear changes in BAX or pro-caspase- 9 or -3 levels. However, PARP cleavage was clearly evident in A2780 cells and together with the fact that $\mathrm{zVAD}$-fmk strongly suppressed DOX-induced apoptosis, we postulate that other yet unconfirmed mechanisms of caspasedependent apoptosis are activated, such as the extrinsic pathway and caspase-8. The opposite holds true for NeRCaMs in which DOX activated p53 as shown by caspase- 9 and PARP cleavage, whereas the addition of $\mathrm{z}$-VAD-fmk only partially suppressed apoptosis indicative of caspase-independent cell death. In NeRCaMs, the observed caspase- 9 activation seems to be merely a co-phenomenon of DOX-induced apoptosis. In line with that, Youn et al (2005) reported that DOX-induced death of the rat cardiac muscle cell line $\mathrm{H} 9 \mathrm{c} 2$ was associated with $\mathrm{p} 53$ upregulation and caspase-independency. Altogether, this indicates the involvement of caspase-independent apoptotic routes in mediating death in cardiac myocytes by DOX. This cannot be generalised because in other cell types (in our study and in previous reports) caspases seem to play a role in DOX-induced cell death (Nakamura et al, 2000; Grassilli et al, 2004; Kalivendi et al, 2005). Together this supports the idea that more than one mechanism can mediate programmed cell death, which depends on both the death stimulus provided and the cell type studied (Bröker et al, 2005). MonoHER appears to protect against these diverse DOX-induced cell death signals, possibly because of the ability of monoHER to neutralise ROS. OVCAR-3 cells were different in their response to DOX compared to the other cell types. They showed hardly any apoptosis within the concentration range of $0.5-10 \mu \mathrm{M}$, which is comparable to clinically achieved concentrations of DOX $(0.3-$ $5 \mu \mathrm{M})$ (Gerwitz, 1999). MonoHER did cause cell cycle delay in G2/M in these cells but did not affect the small amount of DOX-induced cell death.

The finding that monoHER not only suppresses apoptosis in endothelial cells and cardiomyocytes at clinically relevant concentrations of DOX, but also in ovarian cancer cells raises the question whether monoHER may reduce the antitumour effects of DOX in the clinic. It should be noted that in the present study a concentration of $1 \mathrm{~mm}$ monoHER is used. This concentration is about threefold or sevenfold higher than the maximal peak plasma concentrations of monoHER found in the clinic $(360 \mu \mathrm{M})$ during the phase I study (Willems et al, 2006) or in mice $(131 \mu \mathrm{M})$ under protecting conditions (Abou El Hassan et al, 2003c). Thus, monoHER provides a potent protective effect against various routes of doxorubicin-induced cell death allowing an efficient protection of heart and endothelial cells reported previously as major targets in doxorubicin-induced cardiotoxicity. Importantly, the present study addresses the necessity not to raise the dose of monoHER above the presently used $1500 \mathrm{mg} \mathrm{m}^{-2}$ to avoid 
apoptosis-protecting concentrations which might adversely affect the antitumour activity of DOX.

Finally, we postulate that the tendency of monoHER to protect normal cells more than cancer cells may be attributed to the inherent proliferation capacity of cancer cells, even in confluent cultures as used in this study where the growth of tumour cells is less affected by contact inhibition. It can be envisioned that in slow- or non-proliferating cells, such as normal cardiomyocytes and endothelial cells, monoHER predominantly acts against the apoptotic effects of DOX and consequently offers more protection. This is supported by our results showing restricted monoHER protection of confluent but not proliferating endothelial cells after DOX treatment in vitro (Abou El Hassan et al, 2003d). On the other hand, the different effects of monoHER in terms of apoptosis suppression may reflect the activity of the intrinsic ROS defence systems present in cells, which may also be associated with different mechanisms of cell death activation. In this respect, multiple antioxidant defence systems/enzymes (for example, glutathione, thioredoxin and SOD) are active to varying degrees in different cell types thereby forming complex ROS-neutralising networks that are related to apoptosis (Haddad, 2004). In addition,

\section{REFERENCES}

Abou El Hassan MAI, Heijn M, Rabelink MJWE, van der Vijgh WJ, Bast A, Hoeben RC (2003a) The protective effect of cardiac gene transfer of $\mathrm{CuZn}$-sod in comparison with the cardioprotector monohydroxyethylrutoside against doxorubicin-induced cardiotoxicity in cultured cells. Cancer Gene Ther 10: $270-277$

Abou El Hassan MAI, Kedde MA, Zwiers UTH, Bast A, van der Vijgh WJF (2003b) The cardioprotector monoHER does not interfere with the pharmacokinetics or the metabolism of the cardiotoxic agent doxorubicin in mice. Cancer Chemother Pharmacol 51: 306-310

Abou El Hassan MAI, Kedde MA, Zwiers UTH, Torun E, Haenen GRMM, Bast A, van der Vijgh WJF (2003c) Bioavailability and pharmacokinetics of the cardioprotecting flavonoid monohydroxyethylrutoside in mice. Cancer Chemother Pharmacol 52: 371-376

Abou El Hassan MAI, Verheul HMW, Jorna AS, Schalkwijk C, van Bezu J, van der Vijgh WJF, Bast A (2003d) The new cardioprotector Monohydroxyethylrutoside protects against doxorubicin-induced inflammatory effects in vitro. Br J Cancer 89: 357-362

Binaschi M, Capranico G, Dal Bo L, Zunino F (1997) Relationship betweenlethal effects and topoisomerase II-mediated double-stranded DNA breaks produced by anthracyclines with different sequence specificity. Mol Pharmacol 51: 1053-1059

Bröker LE, Kruyt FAE, Giaccone G (2005) Cell death independent of caspases: a review. Clin Cancer Res 11: 3155-3162

Camarda G, Binaschi M, Maggi CA, Goso C (2002) Nuclear factor- $\kappa$ B, induced in human carcinoma cell line A2780 by the new anthracycline MEN 10755, is devoid of transcriptional activity. Int J Cancer 102: 476-482

Capranico G, Kohn KW, Pommier Y (1990) Local sequence requirements for DNA cleavage by mammalian topoisomerase II in the presence of doxorubicin. Nucleic Acids Res 18: 6611-6619

Childs AC, Phaneuf SL, Dirks AJ, Phillips T, Leeuwenburgh C (2002) Doxorubicin treatment in vivo causes cytochrome $\mathrm{C}$ release and cardiomyocyte apoptosis, as well as increased mitochondrial efficiency, superoxide dismutase activity, and Bcl-2: Bax ratio. Cancer Res 62: $4592-4598$

Gewirtz DA (1991) Does bulk damage to DNA explain the cytostatic and cytotoxic effects of topoisomerase II inhibitors? Biochem Pharmacol 42: $2253-2258$

Gerwitz DA (1999) A critical evaluation of the mechanism of action proposed for the antitumor effects of the anthracycline antibiotics adriamycin and daunorubicin. Biochem Pharmacol 57: 727-741

Gouaze V, Mirault ME, Carpentier S, Salvayre R, Levade T, Andrieu-Abadie N (2001) Glutathione peroxidase-1 overexpression prevents ceramide production and partially inhibits apoptosis in doxorubicin-treated human breast carcinoma cells. Mol Pharmacol 60: 488-496

Grassilli E, Ballabeni A, Maellaro E, Del Bello B, Helin K (2004) Loss of $M Y C$ confers resistance to doxorubicin-induced apoptosis by preventing cardiomyocytes were reported to have intrinsically low levels of antioxidant enzymes that may explain the potent protective function of monoHER in these cells (Hrdina et al, 2000). Also high activity of the MRP1/ GS-X pump in these cells was reported (Krause et al, 2007), which may export DOX as glutathione-Sconjugate out of the cells, thereby modifying its cytotoxic effects. However, previously we found that monoHER did not affect DOX levels in cardiac cells in mice or influence the biodistribution of DOX (Abou El Hassan et al, 2003b). Thus, although the level of ROS defense is likely to at least partially determine the protective effect of monoHER in cells, the high complexity of these defense mechanisms makes it difficult to discriminate between their relative contribution to monoHER protection and the relevance for counteracting DOX-induced apoptosis, and will require a systematic, more detailed analysis.

\section{ACKNOWLEDGEMENTS}

This work was supported in part by Grant VU-97-1525 from the Koningin Wilhelmina Foundation, Amsterdam, the Netherlands.

the activation of multiple serine protease- and caspase-mediated pathways. J of Biol Chem 279: 21318-21326

Haddad JJ (2004) Hypoxia and the regulation of mitogen-activated protein kinases: gene transcription and the assessment of potential pharmacologic therapeutic interventions. Int Immunopharmacol 4: 1249-1285

Haenen GRMM, Jansen FP, Bast A (1993) The antioxidant properties of five O- (beta-hydroxyethyl) rutosides of the flavonoid mixture Venoruton. Phlebology 1(Suppl): 10-17

Horenstein MS, Vander Heide RS, L'Ecuyer TJ (2000) Molecular basis of anthracycline-induced cardiotoxicity and its prevention. Mol Gen and Metabol 71: $436-444$

Hrdina R, Gersl V, Klimtova I, Simunek T, Machackova J, Adamcova M (2000) Anthracycline-induced cardiotoxicity. Acta Medica 43: $75-82$

Kalivendi S, Konorev EA, Cunningham S, Vanamala SK, Kaji EH, Joseph J, Kalyanaraman B (2005) Doxorubicin activates nuclear factor of activated T-lymfocytes and Fas ligand transcription: role of mitochondrial reactive oxygen species and calcium. Biochem J 389: 527-539

Keizer HG, Pinedo HM, Schuurhuis GJ, Joenje H (1991) Doxorubicin (adriamycin): a critical review of free radical-dependent mechanisms of cytotoxicity. Pharmacol Ther 47: 219-231

Kluza J, Marchetti P, Gallego MA, Lancel S, Fournier C, Loyens A, Beauvillain JC, Bailly C (2004) Mitochondrial proliferation during apoptosis induced by anticancer agents: effects of doxorubicin and mitoxantrone on cancer and cardiac cells. Oncogene 23: 7018-7030

Kotamraju S, Konorev EA, Joseph J, Kalyanaraman B (2000) Doxorubicininduced apoptosis in endothelial cells and cardiomyocytes is ameliorated by nitrone spin traps and ebselen. Role of reactive oxygen and nitrogen species. J Biol Chem 275: 33585-33592

Krause MS, Oliveira Jr LP, Silveira EMS, Vianna DR, Rossato JS, Almeida BS, Rodrigues MF, Fernandes AJM, Costa JAB, Curi R, Homem de Bittencourt Jr PI (2007) MRP1-GS-X pump ATPase expression: is this the explanation for the cytoprotection of the heart against oxidative stressinduced redox imbalance in comparison to skeletal muscle cells? Cell Biochem Funct 25: 23-32

Lefrak EA, Pitha J, Rosenheim S, Gottlieb JA (1973) A Clinicopathologic analysis of adriamycin cardiotoxicity. Cancer 32: $302-314$

Liu X, Chen Z, Chua CC, Ma YS, Youngberg GA, Hamdy R, Chua BHL (2002) Melatonin as an effective protector against doxorubicin-induced cardiotoxicity. Am J Physiol Heart Circ Physiol 283: $\mathrm{H} 254-\mathrm{H} 263$

Maciag T, Cerundolo J, Ilsely S, Kelley PR, Forand R (1979) An endothelial cell growth factor from bovine hypothalamus: identification and partial characterization. Proc Natl Acad Sci USA 76: 5674-5678

Nakamura T, Ueda Y, Juan Y, Katsuda S, Takahashi H, Koh E (2000) Fasmediated apoptosis in adriamycin-induced cardiomyopathy in rats. Circulation 102: 572-578 
Oliveira PJ, Bjork JA, Santos MS, Leino RL, Froberg MK, Moreno AJ, Wallance KB (2004) Carvedilol-mediated antioxidant protection against doxorubicin-induced cardiac mitochondrial toxicity. Toxicol Appl Pharmacol 200: 159-168

Shacter E, Williams JA, Hinson RM, Senturker S, Lee YJ (2000) Oxidative stress interferes with cancer chemotherapy: inhibition of lymphoma cell apoptosis and phagocytosis. Blood 96: $307-313$

Singal PK, Iliskovic N (1998) Doxorubicin-induced cardiomyopathy. N Eng J Med 339: $900-904$

Spallarossa P, Garibaldi S, Altieri P, Fabbi P, Manca V, Nasti S, Rossettin P, Ghigliotti G, Ballestrero A, Patrone F, Barsotti A, Brunelli C (2004) Carvedilol prevents doxorubicin-induced free radical release and apoptosis in cardiomyocytes in vitro. J Mol Cell Cardiol 37: 837-846

Suresh A, Guedez L, Moreb J, Zucali J (2003) Overexpression of manganese superoxide dismutase promotes survival in cell lines after doxorubicin treatment. Br J Haematol 120: 457-463

Swain SM, Whaley FS, Gerber MC, Weisberg S, York M, Spicer D, Jones SE, Wadler S, Desai A, Vogel C, Speyer J, Mittelman A, Reddy S, Pendergrass K, Velez-Garcia E, Ewer MS, Bianchine JR, Gams RA (1997) Cardioprotection with dexrazoxane for doxorubicin-containing therapy in advanced breast cancer. J Clin Oncol 15: 1318-1322

Uberti D, Yavin E, Gil S, Ayasola KR, Goldfinger N, Rotter V (1999) Hydrogen peroxide induced nuclear translocation of p53 and apoptosis in cells of oligodendroglia origin. Brain Res Mol Brain Res 65: $167-175$

van Acker FA, van Acker SABE, Kramer K, Haenen GRMM, Bast A, van der Vijgh WJ (2000) 7-Monohydroxyethylrutoside protects against chronic doxorubicin-induced cardiotoxicity when administered only once per week. Clin Cancer Res 6: 1337-1341

van Acker SABE, Boven E, Kuiper K, van den Berg DJ, Grimbergen JA, Kramer K, Bast A, van der Vijgh WJ (1997) Monohydroxyethylrutoside, a dose-dependent cardioprotective agent, does not affect the antitumor activity of doxorubicin. Clin Cancer Res 3: 1747-1754

van Acker SABE, Towart R, Husken BCP, de Jong J, van der Vijgh WJF, Bast A (1993) The protective effect of Venoruton and its constituents on acute doxorubicin-induced cardiotoxicity. Phlebology Suppl 1: 31-32

Verheul HMW, Jorna AS, Hoekman K, Broxterman HJ, Gebbink MFBG, Pinedo HM (2000) Vascular endothelial growth factor-stimulated endothelial cells promote adhesion and activation of platelets. Blood 96: $4216-4221$

Willems AM, Bruynzeel AME, Kedde MA, van Groeningen CJ, Bast A, van der Vijgh WJF (2006) A phase 1 study of monohydroxyethylrutoside in healthy volunteers. Cancer Chemother Pharmacol 57: 678-684

Wu S, Ko YS, Teng MS, Ko YL, Hsu LA, Hsueh C, Chou YY, Liew CC, Lee YS (2002) Adriamycin-induced cardiomyocyte and endothelial cell apoptosis: in vitro and in vivo studies. J Mol Cell Cardiol 34: 1595-1607

Xu MF, Tang PL, Oian ZM, Ashraf M (2001) Effects by doxorubicin on the myocardium are mediated by oxygen free radicals. Life Sci 68: 889-901

Yamanaka S, Tatsumi T, Shiraishi J, Mano A, Keira N, Matoba S, Asayama J, Fushiki S, Fliss H, Nakagawa M (2003) Amlodipine inhibits doxorubicin-induced apoptosis in neonatal rat cardiac myocytes. $\mathrm{J} \mathrm{Am}$ Cell Cardiol 41: 870-878

Youn HJ, Kim HS, Jeon MH, Lee JH, Seo YL, Lee YJ, Lee JH (2005) Induction of caspase-independent apoptosis in H9c2 cardiomyocytes by adriamycin treatment. Mol Cell Biochem 270: 13-19 